\title{
Influence of material plasticity change on the evolved heat quantity of constructional steel subjected ECAP
}

by E.S. Lukin, A.M. Ivanov

Institute of physical and technical problems of the North SB RAS, Yakutsk, Russia

\begin{abstract}
The results related to the evaluation of stored energy in the process of plastic deformation of the structural steel Fe360 subjected to equal channel angular pressing are presented. Stored energy was determined as the difference between the plastic deformation work and evolved heat. The heat evolved in the process of plastic deformation was determined by solving the heat conduction equation simultaneously with the use of experimental temperature function. Temperature measurements during the static tensile tests were conducted using an FPAbased infrared camera.
\end{abstract}

Keywords: Equal channel angular pressing; Stored energy; Evolved heat; Plastic strain; Heat conduction equation; Heat source

\section{Introduction}

At present materials with ultra-fine grained structure are widely investigated. These materials have the unique structure and high mechanical characteristics. One of the effective methods of making metals with ultrafine grained structure is the equal channel angular pressing (ECAP). ECAP permits to obtain a nano structural volumetric metal workpiece by refining its grain structure [1].

Steels subjected to ECAP possess high strength, at the same time they have low plasticity. For example, the yield strength and ultimate strength of steel Fe360 in the initial condition are $330 \mathrm{MPa}$ and $500 \mathrm{MPa}$, and after ECAP - 825 MPa and $835 \mathrm{MPa}$, respectively. But results of impact test of Fe360 steel after ECAP are lower than in the initial condition. It is connected with the decrease in material plasticity.

Generally, plastic deformation of the structural steel is accompanied with the generation and motion of dislocations. Change in the density and configuration of the defects always leads to energy dissipation, which causes the specimen temperature increase. The phenomenon of temperature increase in the process of plastic deformation of solids is known as thermoplastic effect.

The part of work of plastic deformation $A_{P}$ is absorbed by a material while the another part is transformed into released heat $Q$. Thus the stored energy $E_{S}$ is determined as a difference between the work of plastic deformation and the heat released into surroundings [2]:

$$
d E_{S}=d A_{P}-d Q
$$

Work of plastic deformation is usually determined from the stress-strain curve. The heat $Q$ can be evaluated with the use of calorimeter [3,4]. However, the calorimetric method is limited by its low speed of response [4].

Besides, the investigations of deformation in metals and steels are sometimes carried out with the use of infrared imaging cameras [5 - 7]. In this case, the change in sample temperature during deformation is measured. However, the correct determination of the released heat during deformation remains the difficult problem and needs to be studied. In the work by E.A. Pieczyska, S.P. Gadaj, W.K. Nowacki, the heat $Q$ can be determined by simulation of the process of sample heating during deformation by applying electrical power $P(t)$ in such a way that the temperature increase with time $t$ during the simulation is identical with that measured during tensile testing [6].

\section{The materials and instruments tested}

The goal of the present work is to evaluate the stored energy in the process of plastic deformation of the structural steel subjected to ECAP. The chemical composition of the Fe360 steel was 0.15 wt $\% \mathrm{C}, 0.2 \mathrm{wt} \% \mathrm{Si}$, 0.52 wt $\% \mathrm{Mn}, 0.17 \mathrm{wt} \% \mathrm{Cr}, 0.13 \mathrm{wt} \% \mathrm{Ni}$, and $0.25 \mathrm{wt} \% \mathrm{Cu}$. The cylindrical workpieces with diameter of $0.02 \mathrm{~m}$ and length of $0.1 \mathrm{~m}$ from the Fe360 steel were subjected to ECAP at the routs $\mathrm{C}$ or $\mathrm{B}_{\mathrm{c}}$. The angle between channels of the pressform is equal to $120^{\circ}$. Number of cycles of pressuring $n$ was 2 or 8 .

The strength characteristics of Fe360 steel after ECAP by the route $B_{c}$ and $C$ are presented in the table 1 . The average grain size after ECAP by the route $B_{c}$ at 2 and 8 pressure cycles is $11.0 \mu \mathrm{m}$ and $7.5 \mu \mathrm{m}$, respectively; by the route $C$ at 2 and 8 cycles it is $10.6 \mu \mathrm{m}$ and $6.6 \mu \mathrm{m}$, respectively. The smallest grain size and the highest strength are obtained by the route $C$ at 8 cycles of pressuring.

After ECAP the standard flat specimens for the static tensile test were made from those workpieces. Rate of deformation during the test was $2.4 \times 10^{-3} \mathrm{~s}^{-1}$. Dimensions of the tested specimens were $0.05 \mathrm{~m}$ (length), 0.0055 
$\mathrm{m}$ (width), and $0.0025 \mathrm{~m}$ (thickness). Tensile tests were performed on the "UTS-20k" testing machine with a constant strain rate.

Table 1.The strength characteristics of Fe 360 steel after ECAP
\begin{tabular}{|c|l|l|}
\hline $\begin{array}{l}\text { Type of ECAP } \\
\text { route and number } \\
\text { of pressuring cycles, } \\
n\end{array}$ & $\begin{array}{l}\text { Yield } \\
\text { strength, } \\
\mathrm{MPa}\end{array}$ & $\begin{array}{l}\text { Ultimate } \\
\text { tensile } \\
\text { strength, } \\
\mathrm{MPa}\end{array}$ \\
\hline $\mathrm{B}_{\mathrm{c}}, n=2$ & 780 & 820 \\
\hline $\mathrm{B}_{\mathrm{c}}, n=8$ & 810 & 830 \\
\hline $\mathrm{C}, n=2$ & 780 & 825 \\
\hline $\mathrm{C}, n=8$ & 845 & 860 \\
\hline
\end{tabular}

Temperature measurements during the specimen deformation were performed using the infrared thermography system TKVr-IFP/“SVIT" equipped with a computer. The temperature sensitivity of the infrared camera (NETD at $30{ }^{\circ} \mathrm{C}$ ) was $0.028^{\circ} \mathrm{C}$. The field of view was about $0.09 \times 0.09 \mathrm{~m}$ at the distance between the camera and specimen being $0.3 \mathrm{~m}$. IR images were stored in the computer memory at the frequency of 20 frames per second. The sensitivity spectral range of the device was $2.45 \div 3.05 \mu \mathrm{m}$. The analysis of both surface temperature map and stress diagram was carried out to evaluate the energy stored during plastic deformation. The stress-strain diagram of Fe360 steel in the initial state 1 and the temperature change curve 2 of the specimen obtained by the infrared thermography system are presented in figure 1 .

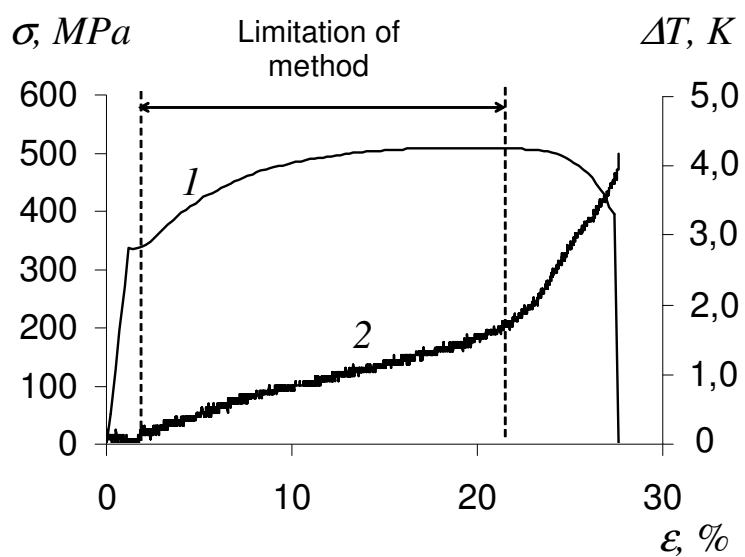

Fig.1. Stress-strain diagram of Fe360 steel in initial state 1 and temperature change curve 2 of the specimen.

\section{Work of plastic deformation}

When material is deformed, a certain fraction of total work $A$ is extended on the work of elastic deformation $A_{e}$ and another one - on the work of plastic deformation $A_{P}$. From this it follows that

$$
A_{P}=A-A_{e}
$$

The principle of determining the work of plastic deformation $A_{P}$ during the tensile test is presented in figure 2, where $\sigma$ is the stress, $\mathcal{E}$ is the strain. The total work $A$ is determined as the shaded area between the stressstrain curve 1 and the straight line 2 . Work of the elastic deformation $A_{e}$ is shown as a twice shaded area between the straight lines 2 and 3. 


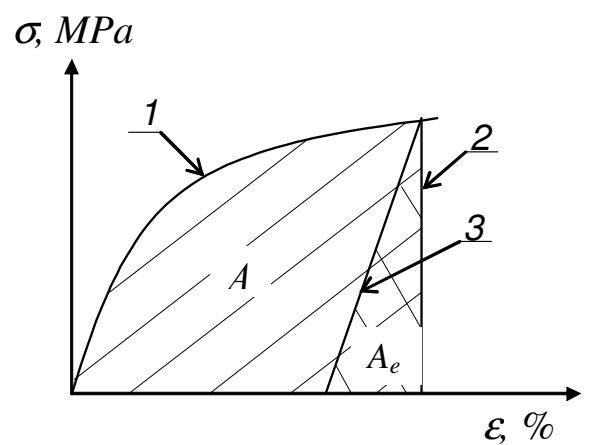

Fig. 2. Principle of determination of the work of plastic deformation during tensile test

\section{Evaluation of the evolved heat}

The heat evolved in the process of plastic deformation is determined by solving the heat conduction equation simultaneously with the use of infrared radiation measurement data.

The evolved heat $Q$ during deformation is evaluated from the solution of one-dimensional heat conduction equation with a heat source $q(t)$ :

$$
\frac{\partial T(x, t)}{\partial t}=a \frac{\partial^{2} T(x, t)}{\partial x^{2}}--v\left(T(x, t)-T_{c}\right)+\frac{q(t)}{c \rho} .
$$

Here, $a$ is the temperature conductivity, $v$ is the thermal diffusivity, $c$ is the heat capacity, $\rho$ is the density, $T(x, t)$ and $T_{c}$ are the distribution of temperature on the surface of the specimen and the temperature of surroundings, respectively. Within this problem, the specimen was simulated as an axisymmetric finite-size bar with known boundary conditions:

$$
T(x, 0)=T_{c}, T(0, t)=T_{c}, T(l, t)=T_{c} .
$$

This method has some limitations and can be used of the linear hardening stage only (figure 1.).

Solutions of the heat conduction equation (3) for the heat source are:

$$
q(t)=\frac{\Delta \bar{T}(x, t)}{a_{1}-a_{2} \cdot \exp \left[-b_{1} \cdot t\right]-a_{3} \cdot \exp \left[-b_{2} \cdot t\right]},
$$

where $a_{1}, a_{2}, a_{3}, b_{1}$, and $b_{2}$ are the constants dependent on the length of a bar, thermal conductivity, density, and heat capacity. The temperature distribution $\Delta \bar{T}(x, t)$ is obtained empirically with the use of the infrared system (figure 1). The evolved heat $q$ (Eq. (6)) can be obtained from the integration of solutions (5)

$$
q=\int_{0}^{t} q(t) \cdot d t .
$$

\section{Results}

The dependence of the specific work of plastic deformation $a_{P}$, specific stored energy $e_{S}$ and evolved heat $q$ on strain of the steel $\mathrm{Fe} 360$ at the initial state in the tensile tests are presented in figure 3.

It is seen that the amount of evolved heat makes up to $30 \%$ of work of plastic deformation, and the rest of this work is stored by the material.

Work of plastic deformation $a_{P}$, stored energy $e_{S}$ and evolved heat $q$ of the steel Fe360 after ECAP by the route $B_{c}$ at $n=2$ cycles of pressure are presented in figure 4 . 
e, $M J / m^{3}$

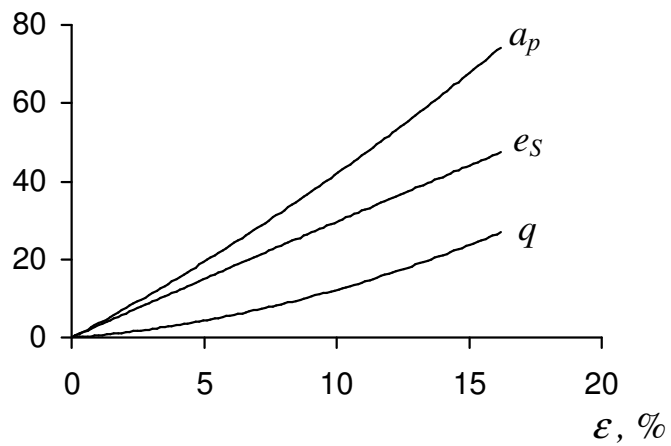

Fig. 3. Dependence of the specific plastic work ap, stored energy $e_{S}$ and evolved heat $q$ of the steel Fe360 in initial condition verses elongation.

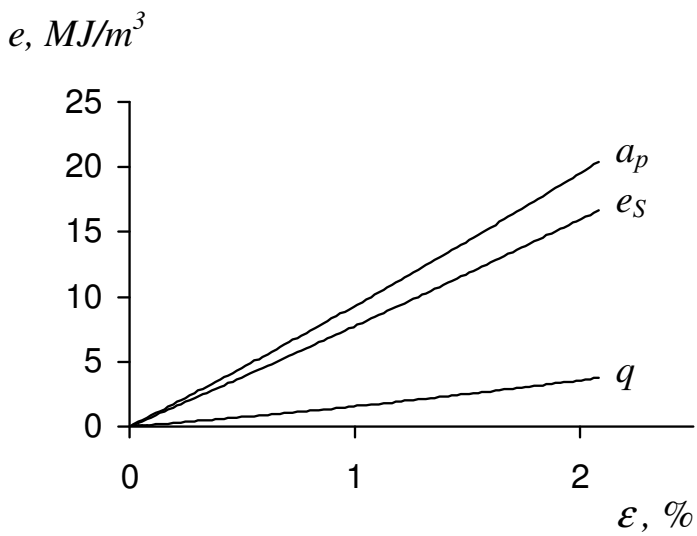

Fig. 4. Dependence of the specific plastic work ap, storage energy es and evolved heat $q$ of the steel Fe360 after ECAP by the route $B_{c}$ at 2 cycles of pressure verses elongation.

In the above case the evolved heat makes up only $10 \div 15 \%$ of the work of plastic deformation. The greater part of plastic deformation is stored by the material. The amount of the evolved heat for the steel subjected to ECAP is less than that for the material in the initial condition. As it is seen, the absolute value of the stored energy for the steel subjected to ECAP is less then for the steel in the initial state. However, stored energy of the steel after ECAP per unit of elongation makes $\approx 8.1 \mathrm{MJ} / \mathrm{m}^{3}$ and for the steel in the initial state consist $\approx 3.1 \mathrm{MJ} / \mathrm{m}^{3}$ only. This fact explains why the strength of the steel after ECAP is higher than that for the steel in the initial state.

\section{Conclusions}

Thus, solution of the inverse problem of conductivity allows to evaluate the amount of heat evolved under the influence of thermoplastic effect with taking into account the heat dissipated into surroundings. The above described calculation-experimental technique exploiting infrared imaging camera allows to determine the energy stored by the material at the static tensile test of specimens. This method is more preferable then calorimetric method which is having low speed of response $[3,4]$ and method based on simulation of the process of sample heating which suggested by E.A. Pieczyska, S.P. Gadaj, W.K. Nowacki [6].

In the work by G.I. Taylor, H. Quinney the evolved heat for the copper makes nearly $80 \div 90 \%$ of the work of plastic deformation [2]. In the present work, the evolved heat for the steel Fe360 in initial state makes nearly 30 $\%$. Evolved heat for the steel Fe360 after ECAP possessed low plasticity is less then $15 \%$. Therefore the evolved heat depends on material plasticity. Materials with high plasticity is dissipate more energy into released heat while the material with low plasticity is stored most part of cold working. This result is confirmed by the data obtained by E.A. Pieczyska, S.P. Gadaj, W.K. Nowacki, where the amount of the evolved heat for the annealed stainless steel possessed average plasticity is makes $60-70 \%$ of the work of plastic deformation [6].

It is shown that the amount of the heat evolved during plastic deformation depends on material plasticity. The absolute value of the stored energy for the steel subjected to ECAP is less than for the steel in the initial state. However, the stored energy of the steel after ECAP per unit of elongation is more than that of the steel in the initial state. 


\section{Acknowledgements}

This work has been supported by the Russian Foundation for Basic Research under Grant RFBR No. 0601-96007.

\section{REFERENCES}

[1] R.Z. Valiev, I.V. Alexandrov, Nano structural materials obtained through method of intensive plastic deformation, Logos, Moscow, 2000. (In Russian)

[2] G.I. Taylor, H. Quinney, Proc. Roy. Soc. 143 (1934) 307.

[3] O.P. Maksimkin, M.N. Gusev, Pis'ma v Zhurnal Tekhnicheskoi Fiziki 27 (24) (2001) 85. (In Russian)

[4] I.V. Astafiev, O.P. Maksimkin, Industrial laboratory No. 1 (1995) 44. (In Russian)

[5] W. Oliferuk, Proc. Eurotherm Seminar No. 60 "Quantitative infrared thermography 4", QIRT'98, Lodz, Poland, 2000, pp. 134-139.

[6] E.A. Pieczyska, S.P. Gadaj, W.K. Nowacki, Proc. Eurotherm Seminar No. 64 "Quantitative infrared thermography 5", QIRT'2000, Reims, France, 2000, pp. 260-264.

[7] E.S. Lukin, A.M. Ivanov, B.G. Vainer, Russian Journal of Nondestructive Testing 39 (6) (2003) 472. 
http://dx.doi.org/10.21611/qirt.2008.13_03_04 